\title{
Electrophysiology in the Guillain-Barré Syndrome: Study of 30 Cases
}

\author{
NC KUNDU
}

\section{Summary:}

Thirty consecutive patients diagnosed clinically as Guillain Barré Syndrome (GBS) were enrolled in this study to see the electrophysiological patterns of GBS in Bangladeshi community. Among 30 patients, 25 were male (M: $F=5: 1$ ) and $47 \%$ patients were between 16 and 25 years of age. An antecedent event was present in $67 \%$ of patients. An elevated protein was present in $90 \%$ of cases and a cell

\section{Introduction:}

The term Guillain-Barre syndrome (GBS) defines a recognizable clinical entity that is characterized by rapidly evolving symmetrical limb weakness, loss of tendon reflexes, absent or mild sensory signs, and variable autonomic dysfunction ${ }^{1}$. Guillain-Barre syndrome is now the commonest cause of acute neuromuscular paralysis worldwide affecting patients of all ages and both sexes ${ }^{2}$.

The earliest descriptions of what we know today, as Guillain-Barre syndrome are probably that of Wardrop and Ollivier, in 1834. In 1916 Guillain, Barre, and Strohl described two French soldiers with motor weakness, areflexia and "albuminocytological dissociation" in the cerebrospinal fluid $^{3}$. Subsequently several cases with similar manifestations were reported and this clinical entity was named after Guillain and Barre. The GuillainBarre syndrome, as recognized clinically, was frequently been equated with acute inflammatory demyelinating polyradiculopathy (AIDP), the pathological entity most extensively studied and most frequently reported in older studies ${ }^{4-5}$ and in contemporary reports ${ }^{6-7}$. However, several lines of evidence suggest that the pathological basis for the Guillain-Barre syndrome, as clinically diagnosed, can be broader, as recently reviewed ${ }^{8-9}$. Some suggests that axonal degeneration can be the dominant process 10-11. In the United States, Europe and Australia, the predominant form is AIDP. The concept of axonal

Address of correspondence: Dr. Narayan Chandra Kundu, Assistant Professor Neurology, Ward -21, Rajshahi Medical College Hospital, Rajshahi. count of up to five was present in $94 \%$ of patients. Acute inflammatory demyelinating polyradiculopathy (AIDP) was commonest (33.35\%) followed by acute motor axonal neuropathy (AMAN) which constitute $26 \%$ of patients in electrophysiological study of the enrolled patients. Acute motor sensory axonal neuropathy constitutes $14 \%$ of cases in this series.

(J Bangladesh Coll Phys Surg 2006; 24: 54-60)

Guillain-Barre syndrome was first raised by Feasby et al, who found early axonal degeneration of motor and sensory fibers in five patients with clinically defined Guillain-Barre syndrome. This pattern of GuillainBarre syndrome, termed acute motor sensory axonal neuropathy (AMSAN), is usually associated with a worse prognosis than demyelinating Guillain-Barre syndrome. Studies in northern China and India 12 have identified another form of axonal Guillain-Barre syndrome, termed acute motor axonal neuropathy (AMAN) ${ }^{13}$. It is suggested that AMAN is associated with pure motor axonal involvement, anti-ganglioside GM1 antibodies, or preceding Campylobacter jejoni infection 14-16. Chinese patients with AMAN are reported to often develop hyperreflexia during the early phase of recovery ${ }^{17}$. Preserved or exaggerated tendon reflexes do not usually occur in patients with AIDP or in patients with other peripheral neuropathies.

F wave represent method of looking at the proximal segments of motor nerves and as such can be very important in certain circumstances (e.g. GBS). The absence of $F$ wave has been interpreted as demyelinating conduction block in the proximal nerve segments when distal compound muscle action potentials are preserved. In Guillain-Barre syndrome, peripheral nerve conduction studies are normal in $10 \%$ to $20 \%$ of patients. However, electrophysiological evidence of nerve dysfunction may be present in the proximal portion of the peripheral nerves and thus absence or slowing of $F$ wave may be an isolated conduction abnormality, especially in the early stage of illness. 


\section{Materials and method:}

Place of study:

This study was carried out in the department of neurology, Bangabandhu Sheikh Mujib Medical University (BSMMU) Hospital during the period of July 2000 to March 2002.

Type of study:

This was a prospective clinical and electrophysiological study.

\section{Inclusion criteria:}

Patients who met the diagnostic criteria for GuillainBarre syndrome (Asbury and Cornbalth, 1990) as describe below were included in this study.

I. Features required for diagnosis:
A. Progressive motor weakness of more than one limb.
B. Areflexia.

II. Features strongly supportive of the diagnosis:

\section{A. Clinical:}

1. Progression within four weeks

2. Relative symmetry

3. Mild sensory symptoms or signs

4. Cranial nerve involvement

5. Recovery within four weeks of progression stopping

6. Autonomic dysfunction

Subject: Thirty consecutive patients (25 male and five female) were included in this study. The youngest patient in this series was a 12 years old boy and the eldest case was 67 years old male.

Method: After admission into the Neurology department of BSMMU Hospital, a thorough history including the history of any antecedent events was taken from the patient or patient's attendant. In every case a careful neurological examination was done including the autonomic nervous system. Patients were followed up for respiratory function, blood pressure, pulse, and muscle power. Each of the patients, who were diagnosed clinically as GBS, was investigated for confirming diagnosis by doing cerebrospinal fluid (CSF) study and electrophysiological study. CSF study was done after tenth day of illness and was sent for biochemical, bacteriological and cytological examination. Electrophysiological study was done irrespective of duration of illness. All measurements were done with surface electrodes and measurements were recorded in a form used by Neurology department in BSMMU. Nerves were stimulated using $1 \mathrm{~ms}$ electrical pulses at a repetition rate of one per second with intensity sufficient to elicit maximum amplitude of compound muscle action potential (CMAP) and sensory nerve action potential (SNAP). In addition to distal latency, amplitude and nerve conduction velocity nerves were tested for $\mathrm{F}$ wave. Besides these, some other investigations were done for example, serum electrolytes, blood sugar etc. to exclude any possible secondary causes of muscle weakness, Data were collected by using a questionnaire and analyzed by appropriate statistical method.

Operational definition at electrophysiology:

Acute Inflammatory Demyelinating Polyneuropathy (AIDP):

Reduced conduction velocity;

Conduction block or temporal dispersion;

Prolonged terminal latency; and

Absent $\mathrm{F}$ wave or prolonged $\mathrm{F}$ wave latency.

Acute Motor Axonal Neuropathy (AMAN):

Absent or reduced compound muscle action potential (CMAP);

Normal motor terminal latency and conduction velocity; and

Normal sensory nerve action potential (SNAP).

Acute Motor Sensory Axonal Neuropathy (AMSAN): Absent or reduced SNAP amplitude;

Absent or reduced CMAP amplitude; and

Normal motor terminal latency and nerve conduction velocity.

\section{Results:}

The study population consisted of thirty (30) patients, twenty-five were male and five female. The age distribution of patients is shown in Table-I. The youngest case in this series was a 12 year old boy and the eldest was a 67 year old male. However, most 
(46.67\%) of the patients were in between 16 and 25 years of age. A history of antecedent event was present in $19(66.33 \%)$ cases while $11(33.66 \%)$ patients failed to give any preceding history of an antecedent event. Fever alone or in combination with loose motion was the commonest antecedent event $(36.66 \%)$ followed by loose motion $(23.33 \%)$. No associated condition like trauma, surgery, lymphoma, vaccination history was present in this study group.

Table-I

\section{Showing the distribution of patients according to age groups $(N=30)$}

\begin{tabular}{ll} 
Age group in years & No of patients \\
\hline $0-15$ & $03(10 \%)$ \\
$16-25$ & $14(46.65 \%)$ \\
$26-35$ & $03(10 \%)$ \\
$36-45$ & $06(20 \%)$ \\
$46-60$ & $03(10 \%)$ \\
$>60$ & $01(3.33 \%)$ \\
\hline
\end{tabular}

Seventh cranial nerve was the commonest nerve $(36.66 \%)$ involved in this series and it was bilateral in two third cases. Sensory involvement was present in five $(16.60 \%)$ patients in the form of impairment of pain and touch sensation. Autonomic involvement like tachycardia, bradycardia, hypertension, hypotension or constipation was present in $27 \%$ cases.

Cerebrospinal fluid protein was elevated in $90 \%$ patients. In 28 (93.3\%) cases cerebrospinal fluid total cell count was up to 5 cells $/ \mathrm{mm}^{3}$ and in only two $(6.7 \%)$ patients total cell count was up to 15 cells $/ \mathrm{mm}^{3}$ (Table-II).

\section{Table-II}

\begin{tabular}{lcc}
\multicolumn{3}{c}{$\begin{array}{c}\text { Showing results of CSF study in Guillain-Barré } \\
\text { syndrome patients }\end{array}$} \\
Parameter & Elevated & Normal \\
\hline Protein & $27(90 \%)$ & $3(10 \%)$ \\
Cell count & $2(6.70 \%)$ & $28(93.30 \%)$ \\
\hline
\end{tabular}

The commonest pattern (33.33\%) in electrophysiology was AIDP followed by AMAN and combination of AMAN and AIDP patterns, both constitute about $26.66 \%$ of cases. Acute motor sensory axonal neuropathy constitute about $14 \%$ of patients (Table-III). In Table-IV and Table - V details of nerve conduction study and findings of CSF examination of selected patients are presented.

Table-III

Showing electro physiologically defined groups of Guillain-Barré syndrome

Electro physiologically Number of patients defined group

\begin{tabular}{ll}
\hline AMAN & $04(13.33 \%)$ \\
AMSAN & $08(26.66 \%)$ \\
AIDP & $10(33.33 \%)$ \\
AMAN and AIDP & $08(26.66 \%)$ \\
\hline
\end{tabular}

Table-IV

Showing the figures of nerve conduction study (NCS) at median nerve of few Guillain-Barré syndrome cases

\begin{tabular}{llllll} 
Case No & NCS Summary & Motor Study & & & Sensory Study \\
& & NCV & Amplitude & F wave & Amplitude \\
\hline 1 & Axonal (motor) \& demyelinating & $50.23 \mathrm{msec}$ & $5.5 \mathrm{mv}$ & Absent & $17.1 \mathrm{mv}$ \\
2 & Axonal motor sensory & $52.10 \mathrm{msec}$ & $4.9 \mathrm{mv}$ & 26.3 & $8.50 \mathrm{mv}$ \\
3 & Demyelinating & $32.80 \mathrm{msec}$ & $12 \mathrm{mv}$ & Absent & $18.20 \mathrm{mv}$ \\
5 & Axonal motor & $52.10 \mathrm{msec}$ & $4.7 \mathrm{mv}$ & 26.7 & $20.21 \mathrm{mv}$ \\
13 & Demyelinating & $37.23 \mathrm{msec}$ & $11.4 \mathrm{mv}$ & 27.1 & $17.2 \mathrm{mv}$ \\
22 & Axonal (motor) \& demyelinating & $51.12 \mathrm{msec}$ & $4.7 \mathrm{mv}$ & 41.24 & $17.4 \mathrm{mv}$ \\
24 & Axonal motor & $52.15 \mathrm{msec}$ & $4.6 \mathrm{mv}$ & 26.15 & $21.5 \mathrm{mv}$ \\
30 & Demyelinating & $39.12 \mathrm{msec}$ & $12.10 \mathrm{mv}$ & Absent & $14.20 \mathrm{mv}$ \\
\hline
\end{tabular}




\section{Table-V}

\section{Showing the summary of nerve conduction study at median nerve and figures of CSF study}

of Guillain-Barré syndrome cases

\begin{tabular}{llllll} 
Case No. & NCS Summary & $\begin{array}{l}\text { CSF Study } \\
\text { Protein }(\mathrm{mg} / \mathrm{dl})\end{array}$ & Days from onset & Sex & Age \\
\hline 1 & Axonal (motor) and demyelinating & 100 & 12 & $\mathrm{M}$ & 32 \\
2 & Axonal motor sensory & 180 & 13 & $\mathrm{M}$ & 20 \\
3 & Demyelinating & 200 & 10 & $\mathrm{M}$ & 56 \\
5 & Axonal motor & 75 & 12 & $\mathrm{M}$ & 60 \\
9 & Demyelinating & 28 & 15 & $\mathrm{M}$ & 33 \\
22 & Axonal (motor) and demyelinating & 145 & 11 & $\mathrm{M}$ & 8 \\
23 & Demyelinating & 136 & 12 & $\mathrm{~F}$ & 25 \\
30 & Axonal motor & 32 & 14 & $\mathrm{M}$ & 36 \\
\hline
\end{tabular}

F wave was absent or $\mathrm{F}$ wave latency was prolonged in four $(50 \%)$ patients among eight cases in whom it was done within seven days of onset of illness. Fwave parameters were abnormal in eight $(36.36 \%)$ cases among patients who presented after seven days of onset of the disease. Compound muscle action potential (CMAP) was abnormal in three cases $(37.50 \%)$ out of eight patients who presented within seven days of illness, and in 17 (77.27\%) patients out of 22 CMAP were of low amplitude when it was done after seven days (Table-VI).

\section{Table-VI}

\section{Evolution of nerve conductive study changes in Guillain-Barré syndrome cases}

\begin{tabular}{llll} 
Changes & $\begin{array}{l}\text { Day } 1 \text { to } 7 \\
(\mathrm{n}=8)\end{array}$ & $\begin{array}{l}\text { Day } 7 \text { to } 21 \\
(\mathrm{n}=22)\end{array}$ & $\begin{array}{l}\text { Total number of patients } \\
(\mathrm{n}=30)\end{array}$ \\
\hline
\end{tabular}

F waves:

$\begin{array}{clll}\text { Abnormal } & 04(50 \%) & 08(36.36 \%) & 12(40 \%) \\ \text { Absent } & 03(75 \%) & 06(75 \%) & 09(75 \%) \\ \text { Prolonged } & 01(25 \%) & 02(25 \%) & 03(25 \%) \\ \text { Normal } & 04(50 \%) & 12(63.64 \%) & 16(60 \%)\end{array}$

SNAP response:
Abnormal
$01(12.5 \%)$
$04(18.18 \%)$
$05(16.67 \%)$

CMAP response:

Low amplitude 


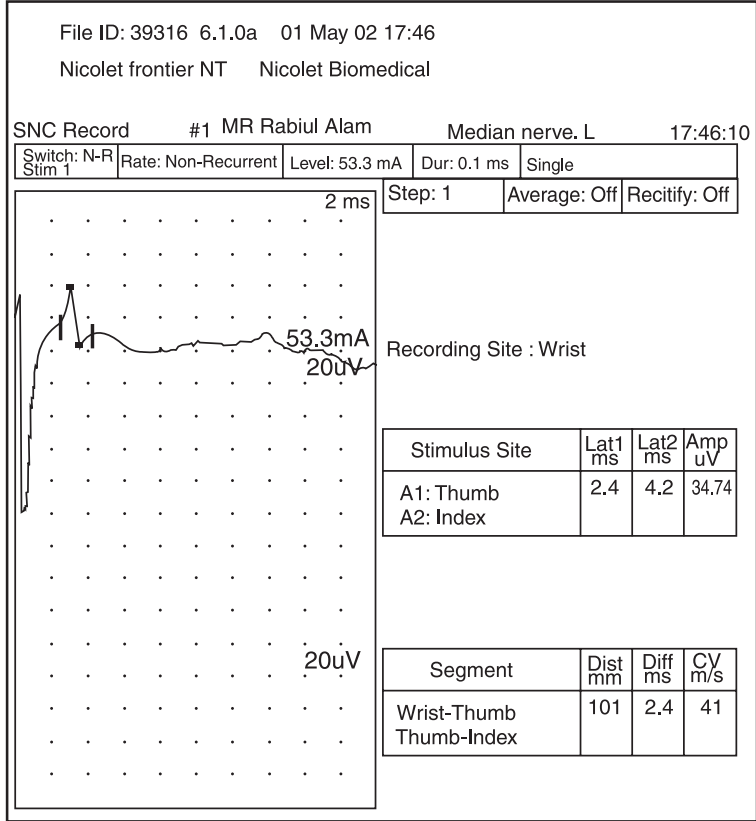

Fig.-1: Showing sensory nerve conduction in a patient of Guillain Barre syndrome.

\section{Discussion:}

The present study was undertaken to evaluate the electrophysiological changes in Guillain-Barre syndrome patients in Bangladeshi population. The standard values used at BSMMU electrophysiology laboratory were taken as control.

Male patients outnumbered female patients, as this study showed males suffered as much as five times (M: $\mathrm{F}=5: 1)$. Though some studies showed males appeared to be affected more commonly ${ }^{18-19}$, the outstanding male predominant involvement in this study was quite remarkable. This may be a chance finding or may be explained on the facts that female patients fail to reach to a tertiary center, like this, for treatment because of customs and religious background or other social factors.

The age distribution curve showed $47 \%$ of patients were between 16 and 25 years of age. The next common age of presentation was between 36 and 45 years $(20 \%)$. This was corroborated with other studies where the investigators showed that the young adults between 15 and 25 years are peak age group for suffering from Guillain-Barre syndrome ${ }^{18,20}$.

The presence of antecedent events was present in two third of patients $(67 \%)$ in the preceding weeks (one to

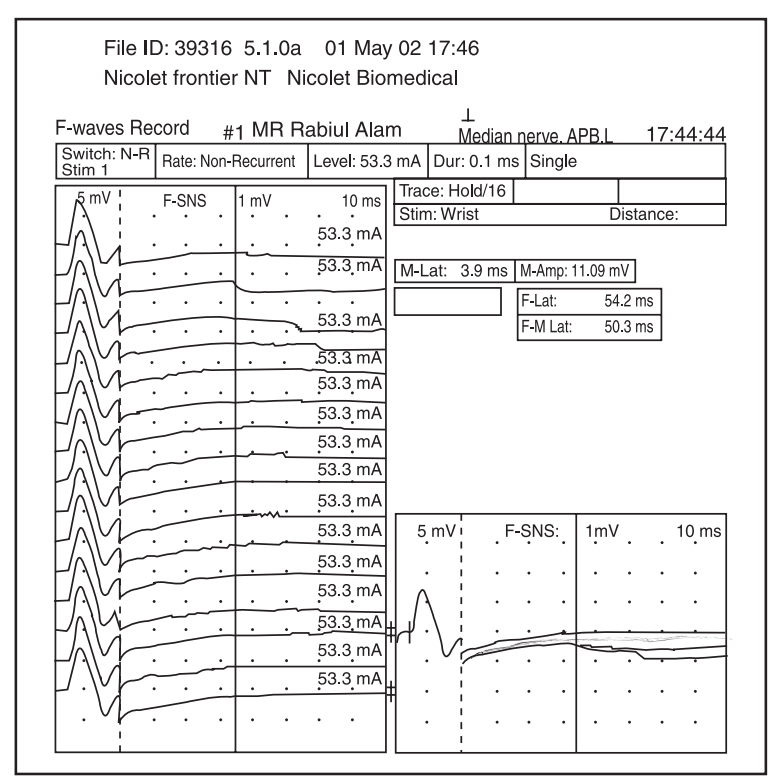

Fig.-2: Figure-2 : Showing F-waves recording of a patient of Guillain-Barré syndrome.

four weeks) and this finding was well in association with other studies ${ }^{21-22}$.

Cranial nerve involvement was present in $46.66 \%$ cases and seventh cranial nerve was the commonest $(78.50 \%)$ and it was bilateral in two third cases. This finding is consistent with two other studies, ${ }^{23-24}$ where cranial nerve involvement was present in 55\% and $53 \%$ of cases respectively.

Features of autonomic nerve involvement such as sinus tachycardia and bradycardia, hypertension and postural hypotension, constipation, anhydrosis or excessive sweating were present in $27 \%$ of patients. This finding is quite low when compared with the study carried out by Singh et al where they showed two third of their cases had features of autonomic nerve involvement ${ }^{25}$. However, these features should be considered carefully during patient management to avoid catastrophe.

Cerebrospinal Fluid study revealed presence of elevated protein in $90 \%$ of cases, which were more or less well correlated ${ }^{22}$. The cell count in cerebrospinal fluid was up to 5 cells $/ \mathrm{mm}^{3}$ in $94 \%$ of patients and in only $6 \%$ of cases it was up to 15 cells/ $\mathrm{mm}^{3}$. This study restated the old saying "cyto-albumino dissociation" is a characteristic feature of GBS. 
F wave was absent or $\mathrm{F}$ wave latency was prolonged in four $(50 \%)$ patients among eight cases in whom it was done within seven days of onset of illness. Fwave parameters were abnormal in eight $(36.36 \%)$ cases among patients who presented after seven days of onset of the disease. Thus this study showed that Fwave abnormalities are more useful in assessing Guillain-Barre syndrome patients in early days.

Acute inflammatory demyelinating polyradiculopathy is the most prevalent form of GBS in western countries and accounts for $85-90 \%$ of cases $^{26}$. AIDP was found in $85 \%$ of cases and acute axonal forms of GBS in $15 \%$ of cases in a series reported by $\mathrm{Hahn}^{27}$. In this series, AIDP was the commonest electrophysiological variant of GBS (33.35\%). This is quite low in comparison to the western studies as mentioned ${ }^{3-6}$. This study revealed that in $14 \%$ cases there were presence of both motor and sensory axonal damage and this finding was well correlated with other published reports ${ }^{28}$.

In this study, AMAN and a combination of AMAN and AIDP closely follows AIDP, each group constituted about $26 \%$ of cases. This was slightly higher than other reported studies especially from China $28-29$. That is in about, $26 \%$ cases there were presence of both demyelination and axonal changes in the same patient.

As axonal regeneration takes long time, the functional recovery after Guillain-Barré is delayed in whom the axon is the main target of damage. On the other hand remyelination occurs much quickly and thus the chance of recovery following GBS is much better in whom only myelin sheath is involved. Thus the ultimate outcome depends mainly on the pattern of involvement.

This study shows that acute inflammatory demyelinating neuropathy is still the predominant GBS variant in Bangladeshi population but axonal involvement and injury constitute a substantial percentage of GBS cases, which should be sought in clinical and electrophysiological study to foresee the ultimate outcome in GBS.

\section{References:}

1. Olive JM, Castillo C, Castro RG, et al. Epidemiologic study of Guillain-Barre syndrome in children $<15$ years of age in Latin America. J Infect Dis 1997; 175(suppl.): 160-4.
2. Giovannoni G, Hartung HP. The immunopathogenesis of multiple sclerosis and Guillain-Barre syndrome. Curr Opin Neurol 1996; 9:165-77.

3. Guillain G, Barre JA, Strohl A. Sur un syndrome de radiculo-nevrite hyper albuminos du liquide cephalorachidien sans reaction cellulaire. Bull Soc Med Hop Paris 1916;40: 1462-70.

4. Haymaker W, Kernohan JW. The Landry-Guillain-Barre syndrome. A clinicopathologic report of fifty fatal cases and a critique of the literature. Medicine 1949; 28: 59-141.

5. Asbury AK, Arnason BJ, Adams RD. The inflammatory lesion in idiopathic polyneuritis. Its role in pathogenesis. Medicine 1969; 48: 173-215.

6. Fuller GN, Jacobs JM, Lewis PD, et al. Pseudoaxonal Guillain-Barre syndrome: severe demyelination mimicking axonopathy. A case with pupillary involvement. J Neurol Neurosurg Psychiatry 1992; 55:1079-83.

7. Hall SM Hughes RA, Atikson PF, et al. Motor nerve biopsy in severe Guillain-Barre syndrome. Ann Neurol 1992; 31: $441-4$.

8. Griffin JW, Li CY, Macko C, et al. Early nodal changes in the acute motor axonal neuropathy pattern of Guillain-Barre syndrome. J Neurocytol 1996; 25: 33-51.

9. Thomas PK. The Guillain-Barre syndrome: no longer a simple concept. J Neurol 1992; 239: 361-2.

10. Feasby TE, Gilbert JJ, Brown WF, et al. An acute axonal form of Guillain-Barre polyneuropathy. Brain 1986; 109: $1115-26$

11. Visser LH, van der Meche FGA, van Doorn PA, et al. Guillain-Barre syndrome with out sensory loss: a subgroup with specific clinical, electrodiagnostic and laboratory factor. Brain 1995; 118: 841-47.

12. Wadia RS, Gulwani AV, Chowdhany MR, et al. Acute transient non-inflammatory neuropathy (a possible differential diagnosis of the Guillain-Barre syndrome). Neurol India 1982; 30:113-20.

13. Mckhann GM, Cornbalth DR, Griffin JW. Acute motor axonal neuropathy: a frequent cause of acute flaccid paralysis in China. Ann Neurol 1993; 33: 333-42.

14. Brown WF, Feasby TE. Conduction block and denervation in Guillain-Barre polyneuropathy. Brain 1984; 107: 219-39.

15. Albers JW, Donofrio PD, McGonagle TK. Sequential electrodiagnostic abnormalities in acute inflammatory demyelinating polyradiculoneuropathy. Muscle Nerve 1985; 8: 528-39.

16. Fisher M. An unusual variant of acute idiopathic polyneuritis (syndrome of ophthalmoplegia, ataxia and areflexia). N Engl J Med 1956; 255: 57-65. 
17. Kuwabara S, Yuki N, Koga M. IgG anti GM1 antibody is associated with reversible conduction failure and axonal degeneration in Guillain-Barre syndrome. Ann Neurol 1998; 44: 202-8.

18. Konberg AJ, Pestronk A, Bieser K. Clinical correlates of high titer IgG anti GM1 antibodies. Ann Neurol 1994; 35: 234-7.

19. Jacobs BC, van Doorn PA, Schmitz PIN. Campylobacter jejuni infections and anti GM1 antibodies in Guillain-Barre syndrome. Ann Neurol 1996; 40: 181-7.

20. Mckhann GM, Cornblath DR, Ho TW. Clinical and electrophysiological aspects of acute paralytic disease of children and young adult in northern China. Lancet 1991; 338: 593-7.

21. 28. Paul H, Gordan MD, Asa J. Early Electrodiagnostic finding in Guillain-Barre syndrome. Arch Neurol 2001; 85: 913-18.

22. Ho TW, Mishu B, Li CY, et al. Guillain Barre Syndrome in northern China. Relationship to Campylobactor jejuni infection and anti-glycolipid antibodies. Brain 1995; 11: 597-605.
23. Emilla-Romagna Study Group on Clinical and Epidemiological Problems in Neurology. Guillain-Barre syndrome variants in Emilla-Romagna, Italy, 1992-93: incidence, clinical features and prognosis. J Neurol Neurosurg Psychiatry 1998; 65: 218-24.

24. de Jager AE, Sluiter HJ. Clinical signs in severe GuillainBarre Syndrome: analysis of 63 patients. J Neurol Sci 191; 104:143-50

25. Singh NK, Jaiswal AK, Misra S, et al. Assessment of autonomic dysfunction in Guillain-Barre syndrome and its prognostic implications. Acta Neurol Scand 1987; 75:101-5.

26. Rees JH, Soudain SE, Gregson NA, et al. Campylobacter jejuni infections and Guillain-Barre syndrome. N Engl J Med $1995 ; 333: 1374-9$

27. Yuki N, Hirata K. Preserved tendon reflexes in Campylobacter neuropathy. Ann Neurol 1998; 43: 546-7.

28. Gibbils E, Giebisch U. Natural course of acute and chronic monophasic inflammatory demyelinating polyneuropathy. Acta Neurol Scan 1992; 85: 282-91.

29. Brown WF, Feasby TE, Hahn AF. Electrophysiological changes in the acute 'axonal' form of Guillain-Barre Syndrome. Muscle Nerve 1993; 93: 200-05. 